\title{
Orientações do Serviço Médico de uma Unidade de Referência em Cuidados Paliativos Oncológicos frente à Pandemia de Covid-19
}

https://doi.org/10.32635/2176-9745.RBC.2020v66nTemaAtual.1058

Guidelines of the Medical Service of a Referral Unit in Palliative Oncology Care in face of the COVID-19 Pandemic

Pautas del Servicio Médico de una Unidad de Referencia en Cuidados Oncológicos Paliativos ante la Pandemia de Covid-19

Simone Garruth dos Santos Machado Sampaio'; Andrea Marins Dias²; Renata de Freitas ${ }^{3}$

\section{INTRODUÇÃO}

A pandemia da doença pelo coronavírus 2019 (coronavirus disease 2019 - Covid-19) ${ }^{1}$ trouxe a necessidade de adaptação dos serviços para a manutenção do trabalho assistencial de forma segura para pacientes e profissionais. Pacientes com câncer avançado estão incluídos no grupo de risco para infecção por Covid- $19^{2}$, mas também precisam que seu tratamento seja continuado para o adequado controle de sintomas e qualidade de vida ${ }^{3}$. Em consonância com as orientaçóes da Academia Nacional de Cuidados Paliativos (ANCP) ${ }^{4}$, do Conselho Federal de Medicina $(\mathrm{CFM})^{5}$ e da Associação Médica Brasileira $(\mathrm{AMB})^{6}$, o Serviço Médico da Unidade de Cuidados Paliativos do Hospital do Câncer IV (HC IV) do Instituto Nacional de Câncer José Alencar Gomes da Silva (INCA), especializado e de referência nacional em cuidados paliativos oncológicos, elaborou um plano de ação para o atendimento durante o período da pandemia.

O controle de sintomas e a qualidade de vida do paciente, alinhados a um olhar atento e acolhedor a seus familiares, estão entre os pilares norteadores dos Cuidados Paliativos ${ }^{7}$. Conciliar as recomendaçóes para o atendimento seguro e manter a relação médico-paciente são alguns dos desafios para o paliativista ${ }^{3,4}$.

Outro desafio é a definiçấo de caso suspeito ${ }^{8}$. A dispneia é um dos principais sintomas no câncer avançado ${ }^{9}$ e, também, é um dos sintomas de gravidade que demandam atendimento e internação em pacientes com Covid-19 ${ }^{10}$. Há inúmeros aspectos envolvidos que tornam difícil essa definição. Uma vez definido como suspeito por infecção por Covid-19, o paciente deve ficar internado isolado, sem acompanhante e sem sair do quarto, o que pode gerar uma situação desagradável tanto para o paciente quanto para seus familiares; em evoluindo a óbito, há restriçôes para o reconhecimento do corpo, velório e sepultamento ${ }^{11}$. Por outro lado, se um paciente com infecção por Covid-19 for internado como paciente não suspeito, pode ser vetor tanto para equipe assistencial e de apoio quanto para outros pacientes do setor. Critérios precisos e experiência profissional são extremamente necessários.

\section{ORIENTAÇÕES}

A assistência precisa ser adaptada para colaborar com as orientaçóes governamentais de restrição a deslocamento de pessoas. Como proteçáo aos profissionais e pacientes, sugere-se como objetivos norteadores: manter o menor movimento possível de pacientes na unidade, evitar sobrecarga nos processos de atendimento e para a equipe assistencial; promover que a equipe assistencial e de apoio tenha contato com o menor número de pessoas possível; manter a qualidade do atendimento; e proteger os pacientes que estão no grupo de maior risco.

A escala de serviço deve ser ajustada com intuito de os pacientes serem adequadamente atendidos e os profissionais não ficarem sobrecarregados. É importante conhecer o corpo clínico e as demandas de cada processo de atendimento para eventual remanejamento interno.

Com a liberação pelo $\mathrm{CFM}^{12}$ de teleorientaçáo e telemonitoramento e a posterior ratificação pelo Ministério da Saúde ${ }^{13}$, o uso da telemedicina deve ser visto como um aliado importante no momento atual.

A comunicaçáo entre os processos, especialmente neste período, é um instrumento essencial para o cumprimento dos objetivos.

Os atendimentos nos diversos processos na unidade devem ser avaliados constantemente para certificar que os objetivos estáo sendo atingidos.

\footnotetext{
${ }^{1}$ Doutora. Médica. Unidade de Cuidados Paliativos do Hospital do Câncer IV (HC IV) do Instituto Nacional de Câncer José Alencar Gomes da Silva (INCA). Rio de Janeiro (RJ), Brasil. Orcid iD: https://orcid.org/0000-0001-5537-7399

${ }^{2}$ Graduada. Médica. Unidade de Cuidados Paliativos do HC IV/INCA. Rio de Janeiro (RJ), Brasil. Orcid iD: https://orcid.org/0000-0003-1513-6640

${ }^{3}$ Mestranda. Médica. Unidade de Cuidados Paliativos do HC IV/INCA. Rio de Janeiro (RJ), Brasil. Orcid iD: https://orcid.org/0000-0001-7285-8768

Endereço para correspondência: Simone Garruth dos Santos Machado Sampaio. Rua Visconde de Santa Isabel, 274 - Vila Isabel. Rio de Janeiro (RJ), Brasil. CEP 20560-121. E-mail: simonegarruth@gmail.com
} 
AMBULATÓRIO

- Manter as consultas de primeiro atendimento na unidade e agendar o mais breve possível do encaminhamento.

- Contactar os pacientes por ligaçáo de voz ou videochamada para telemonitoramento e teleorientação sobre quadro clínico e controle de sintomas gradativamente para que todos os pacientes sejam acompanhados. Todos os atendimentos devem ser registrados em prontuário.

- Evitar consultas presenciais caso paciente esteja com sintomas controlados. Fornecer nova receita para que, preferencialmente, um familiar ou outra pessoa designada pelo paciente receba a receita e a medicação para evitar interrupçáo do tratamento. Ajustes possíveis de serem realizados por teleorientação com segurança podem ser realizados.

- Buscar ativamente, por telefone, na véspera da consulta presencial, sintomas sugestivos de infecçáo por Covid-19 no paciente e em familiares. Sendo considerado caso suspeito, avaliar a necessidade da manutenção da consulta presencial. Preferencialmente, a consulta deve ser reagendada para 14 dias após o início dos sintomas; não sendo possível, sinalizar toda a equipe para o adequado isolamento na unidade.

- Rastrear os casos suspeitos de infecção por Covid-19 e orientar sobre isolamento, gravidade e indicaçôes de atendimento presencial. Encaminhar a lista com esses pacientes ao médico do Serviço de Pronto Atendimento (SPA) para ciência e providências, caso haja demanda espontânea.

\section{ASSISTENNCIA DOMIIILIAR}

- Realizar teleorientaçáo e telemonitoramento dos pacientes atendidos pelo processo, de forma gradual, para que todos sejam acompanhados remotamente.

- Priorizar o atendimento presencial a pacientes com sintomas sem controle, postergando visitas médicas em pacientes com quadros compensados.

- Fornecer nova receita para que, preferencialmente, um familiar ou outra pessoa designada pelo paciente receba a receita e a medicaçáo para evitar interrupção do tratamento.

- Rastrear casos suspeitos de infecção por covid-19 e orientar pacientes e/ou familiares sobre isolamento, gravidade e indicaçóes de atendimento presencial. Encaminhar a lista com esses pacientes ao médico do SPA para ciência.

\section{SERVIÇO DE PRONTO ATENDIMENTO}

- Realizar pré-triagem com foco na presença de sintomas sugestivos de infeção por Covid-19 antes de entrar no setor. Encaminhar os casos suspeitos para o local de isolamento e prosseguir lá o atendimento. Atentar para o respeito ao sigilo médico-paciente.

- Evitar internaçóes de casos suspeitos sem gravidade, conforme orientação das autoridades sanitárias ${ }^{10}$.

- Identificar os pacientes com sintomas que possam ser compensados com ajuste de medicaçáo e com suporte do telemonitoramento. Estes deveráo receber nova receita com a medicação adequada e o caso sinalizado ao colega do ambulatório ou da assistência domiciliar para o acompanhamento.

- Tentar reduzir o tempo do paciente nos leitos do SPA, face ao esperado aumento da demanda.

- Definir a necessidade de internação e acelerar a documentaçáo para que o paciente seja encaminhado à internação hospitalar o mais rápido possível para disponibilizar o leito no SPA. Em sendo caso suspeito, o paciente será internado inicialmente na unidade para liberar o espaço físico e posterior definição sobre manutenção na unidade ou transferência, segundo o sistema de regulação do Estado.

- Notificar os casos suspeitos conforme orientaçáo da Comissão de Controle de Infecção Hospitalar $(\mathrm{CCIH})$. Atentar que a responsabilidade de notificar é do profissional que realizar o primeiro atendimento. Caso não seja possível, sinalizar para a $\mathrm{CCIH}$ e para equipe da internação hospitalar para que não haja omissão legal por parte da equipe.

- Receber das equipes do ambulatório e da assistência domiciliar a relaçáo de pacientes com quadro clínico suspeito para ciência e otimização de proteção dos profissionais e demais pacientes, caso haja demanda espontânea por atendimento. Atentar para que o sigilo médico seja resguardado.

\section{INTERNAÇÃO HOSPITALAR}

- Manter um setor para as internaçóes dos casos suspeitos de infecção por Covid-19.

- Não realizar conferência familiar presencial. Orientaçóes devem ser passadas individualmente a familiares e acompanhantes, com acolhimento e disponibilidade.

- Seguir restriçóes de visita conforme determinação da unidade.

- Emitir boletim diário dos pacientes internados por suspeita de Covid-19, uma vez que estes náo devem ter acompanhante. Atentar para a necessidade que alguns familiares possuem de maior acolhimento e acionar a equipe técnica de apoio.

\section{ORIENTAÇ̃̃ES ADICIONAIS}

- A equipe assistencial e a CCIH devem estar alinhadas para orientaçóes e treinamentos. 
- Deve ser criado entre os membros da equipe um canal de comunicação no qual a informação chegue aos interessados de forma célere. $\mathrm{O}$ uso de aplicativos que permitem comunicação em grupo é uma das opções. Atençáo à informaçáo náo relacionada à assistência e respeito ao horário de trabalho devem ser observados, assim como o sigilo com eventuais informaçóes de pacientes.

- Prescrição de nebulização e oxigenioterapia suplementar em casos suspeitos deve ser restrita à necessidade objetiva, face à aerossolização e ao aumento do risco de contágio de Covid-19. Critérios também devem ser utilizados na prescrição de glicemia capilar, uma vez que a limpeza do aparelho é difícil por questóes técnicas.

- As medidas tomadas inicialmente devem constantemente avaliadas e adequadas conforme a necessidade.

\section{CONCLUSÃO}

$\mathrm{O}$ atendimento a pacientes em cuidados paliativos oncológicos precisa ser contínuo apesar do momento adverso. $\mathrm{O}$ uso da tecnologia pode ser um grande aliado no momento atual. Proporcionar ambientes seguros para os profissionais e para os pacientes que precisem de atendimento presencial, seja no domicílio, seja em ambiente hospitalar, é mandatório para todos os serviços de saúde. $\mathrm{O}$ acolhimento a pacientes e a familiares durante o curso da sua doença oncológica não pode ser negligenciado. As estratégias adotadas devem ser regulares e constantemente avaliadas e readequadas.

\section{CONTRIBUIÇÕES}

Simone Garruth dos Santos Machado Sampaio participou da concepção e redação do manuscrito. Andrea Marins Dias e Renata de Freitas participaram da concepção e revisão com contribuiçấo intelectual. Todas as autoras aprovaram a versão final publicada.

\section{DECLARAÇÃO DE CONFLITO DE INTERESSES}

Nada a declarar.

\section{FONTES DE FINANCIAMENTO}

Não há.

\section{REFERÊNCIAS}

1. World Health Organization [Internet]. Geneva: WHO; c2020. WHO Director-General's opening remarks at the media briefing on COVID-19; 2020 Mar 11 [cited
2020 Mar 12]. Available from: https://www.who.int/dg/ speeches/detail/who-director-general-s-opening-remarksat-the-media-briefing-on-covid-19---11-march-2020

2. Wu Z, McGoogan JM. Characteristics of and important lessons from the coronavirus disease 2019 (COVID-19) outbreak in China: summary of a report of 72314 cases from the chinese Center for Disease Control and Prevention. JAMA. 2020;323(13):1239-42. doi: https:// doi.org/10.1001/jama.2020.2648

3. CSU Shiley Institute for Palliative Care [Internet]. San Marcos, CA: CSU Institute for Palliative Care; [2017]. Ballentine JM. The role of palliative care in a COVID-19 pandemic; [2020] [cited 2020 Mar 19]. Available from: https://csupalliativecare.org/palliativecare-and-covid-19/.

4. Academia Nacional de Cuidados Paliativos (BR). Posicionamento da Academia Nacional de Cuidados Paliativos sobre COVID-19 [Internet]. Sáo Paulo: ANCP; [2020] [acesso 2020 abr 20]. Disponível em: https://www.dropbox.com/s/g77qi6xk2jc8rky/FINAL_ ANCP_Ebook_cuidados_COVID-19.pdf?dl=0

5. Conselho Federal de Medicina (BR). Posição do Conselho Federal de Medicina sobre a pandemia de COVID-19: contexto, análise de medidas e recomendaçóes [Internet]. Brasília, DF: CFM; 2020 mar 17 [acesso 2020 mar 18]. Disponível em: http://portal.cfm.org.br/images/stories/ pdf/covid-19_cfm.pdf

6. Associação Médica Brasileira (BR). Diretrizes AMB: COVID-19 [Internet]. São Paulo: AMB; [2020 abr 22] [acesso 2020 abr 30]. Disponível em: https://amb.org. br/wp-content/uploads/2020/04/DIRETRIZES-AMBCOVID-19-22.04.2020.pdf

7. World Health Organization. National cancer control programmes: policies and managerial guidelines [Internet]. 2nd ed. Geneva: WHO; 2002 [cited 2020 Mar 19]. Available from: https://apps.who.int/iris/ handle/10665/42494

8. Mungroo MR, Khan NA, Siddiqui R. Novel coronavirus: current understanding of clinical features, diagnosis, pathogenesis, and treatment options. Pathogens. 2020;9(4):297. doi: https://doi.org/10.3390/ pathogens 9040297

9. Damani A, Ghoshal A, Salins N, et al. Prevalence and intensity of dyspnea in advanced cancer and its impact on quality of life. Indian J Palliat Care. 2018;24(1):4450. doi: https://doi.org/10.4103/IJPC.IJPC_114_17

10. Secretaria de Atenção Primária à Saude. Protocolo de manejo clínico do coronavirus (COVID-19) na atenção primária à saúde [Internet]. Brasília, DF: SAPS; 2020 mar [acesso 2020 mar 30]. Disponível em: https://www. saude.gov.br/images/pdf/2020/marco/20/20200318ProtocoloManejo-ver002.pdf

11. Agência Nacional de Vigilância Sanitária. Nota Técnica GVIMS/GGTES/ANVISA no 04/2020: orientaçôes 
para serviços de saúde: medidas de prevenção e controle que devem ser adotadas durante a assistência aos casos suspeitos ou confirmados de infecçáo pelo novo coronavírus (SARS-CoV-2) [Internet]. Brasília, DF: ANVISA; 2020 jan 30 [atualizada 2020 maio 08; acesso 2020 maio 10]. Disponível em: http:// portal.anvisa.gov.br/documents/33852/271858/ Nota+T\%C3\%A9cnica+n+04-2020+GVIMS-GGTESANVISA/ab598660-3de4-4f14-8e6f-b9341c196b28

12. Conselho Federal de Medicina (BR). Ofício CFM no 1756/2020 - COJUR [Internet]. Brasília, DF: CFM; 2020 mar 19. Assunto: Telemedicina [acesso 2020 mar 20]. Disponível em http://portal.cfm.org.br/images/ PDF/2020_oficio_telemedicina.pdf

13. Ministério da Saúde (BR). Portaria no 467, de 20 de março de 2020. Dispóe, em caráter excepcional e temporário, sobre as açóes de Telemedicina, com o objetivo de regulamentar e operacionalizar as medidas de enfrentamento da emergência de saúde pública de importância internacional previstas no art. $3^{\circ}$ da Lei $\mathrm{n}^{\circ}$ 13.979, de 6 de fevereiro de 2020, decorrente da epidemia de COVID-19 [Internet]. Diário Oficial da União, Brasília, DF; 2020 mar 23. Seção I - Extra, p. 1 [acesso 2020 mar 21]. Disponível em: http://www. in.gov.br/en/web/dou/-/portaria-n-467-de-20-de-marcode-2020-249312996 